\title{
Analysis on the Policy and Motivation of Ma Ying- jeou Authority to EU
}

\author{
Wenting Huang \\ Law of school \\ Guangdong University of Foreign Studies \\ Guangzhou, China
}

\author{
Xiaowei Yuan* \\ Law of school \\ Guangdong University of Foreign Studies \\ Guangzhou, China \\ *Corresponding Author
}

\author{
Shenglong Jiang \\ Law of school \\ Guangdong University of Foreign Studies \\ Guangzhou, China
}

\begin{abstract}
EU plays an important role in international affairs since the founding of it, Taiwan authorities even positions it as sovereign state and one of activity zone importantly. After Ma Ying-jeou comes to power, he intends to develop the relationship between Taiwan and EU by "viable diplomacy". This article study purposes, field and path of Ma Ying-jeou authority to EU's policy, thus analyzing its motivation. This article believes that $\mathrm{Ma}$ Ying-jeou make use of "congressional diplomacy", "visa waiver" to deepen "substantive relationship" for EU politically, and try to integrate into EU economic and trade system economically. The motivations are expand "international space" of Taiwan, getting out from economical dilemma, and external factor is relationship between Taiwan and Japan that drop into trough. On the whole, Although Ma Ying-jeou authority to EU's policy achieved certain results, the prerequisite is mainland policy of "One China", and it is an important caution for Tsai Ing-wen nowadays.
\end{abstract}

Keywords-Taiwan; $\mathrm{EU}$; the policy toward $\mathrm{EU}$; relationship between Taiwan and $E U$

\section{INTRODUCTION}

First of all, the Taiwanese Authority advocated a new diplomatic concept, that is Taipei and Beijing should stop competing in the international arena and thus build mutual trust, which replaced Chen Shui-bian's so-called" beacon diplomacy" since Mr. Ma's taking office in 2008. With this Concept, the Taiwanese Authority abandoned the attempt to establish official diplomatic relations, but to develop the substantial relationship with the EU members. Her two major political objectives are increase the presence of" the Republic of China "in Europe, seeking international sympathy and support ; and to expand her international space with the help of EU, especially joining the functional international organizations. Finally find a new way toward the international community in the way of "dignity" "flexibility" and "pragmatism".

Secondly, the economy is seeking to increase exports to Europe to promote economic development on the island, while hoping to enter into economic and trade agreements with the European Union and integrate into the EU economic and trade system. The Taiwanese economy is export-oriented, rely-on exportation deeply and the EU is its main market. Take the year of 2006, which is before the Economic Crisis, as an example, the exportation took up $63.29 \%$ of Taiwanese GDP in which the EU is it's forth destination, which occupied $11 \%$ of the exportation.

However, with the shock of the Financial Crisis in 2008, this exportation had sharp declined, from the fourth season of 2008, the importation from the EU declined for $1.5 \%$, and the exportation, 24\%. And then, the right of Taiwan cannot guaranteed by law and it is hard to enjoy the favorable policies and difficult to integrate into the trade system of the EU as well, because it has not signed the economy and trade agreements (such as Investment protection agreement) with the latter.

Consequently, the Ma's Administration was eager to regain the exportation to the EU, and try to integrate into its trade system and attract the European investment.

\section{POLICY PROMOTION AREAS}

\section{A. Deepen the Political Relations of "Substantive Diplomacy"}

After Ma Ying-Jeou came to power, the Taiwanese authority strengthened the "congressional diplomacy", and devoted itself to the developed the "substantive political relations" with the European Union. According to incomplete statistics, during the 8 years Ma Ying-Jeou administration, as many as 149 members of the European Parliament to visited Taiwan ,and most of them are relative higher level, including the Vice President of European Parliament, procurator and chairpersons and vice chairpersons of its Committees. The number of members of the "pro-Taiwan group" has risen rapidly from 115 in 2006 to 248 in 2009 .While, during Chen Shuibian's 8 years, only 69 members times visited to Taiwan, and predominantly ordinary members. 
In 2009, Wang Jin-pyng, President of Taiwan's “Legislative Yuan" visited the European Parliament, and received high standard reception, during his visit, besides met Hans-Gert Pottering, the President of the European Parliament, he made a speech in the European Parliament in Brussels for the first time, which beyond the reception he received in 2002.Furthermore, in 2015, Mr. Ma held a video conference with members of the European parliament. The Ma Administration has also pushed forward actively the policy of "visa free" to the EU, which considered as a new breakthrough in promotion" substantive relationship "between Taiwan and Europe by the Taiwan authorities". Therefore, the Taiwan authorities started negotiates with Britain and Ireland, which are the EU member in 2007 to canvass them to give Taiwanese citizens Visa free treatment, and won success in 2009 , and it is regarded as demonstration effect .Moreover, when Romania, Bulgaria and Cyprus still treated this issue with reserve, Taiwan give their citizen this treatment at first, and then success in persuading the EU to adopt its plan in 2010.

The Taiwan authorities show its closed relation with the EU through the "visa free" and endorse its "substantive foreign policy", no wonder Lin Yongle, its "Foreign Affairs Minister" evaluated it very high, and he said that it was "an important breakthrough on diplomatic work toward Europe since more than thirty years.

\section{B. To Build a Closer Economic and Trade Ties}

Since Ma came to power, Taiwan was committed to closer economic and trade relations with the EU, and seeking to increase exports to Europe, to achieve this goal, it must integrate into the existing economic and trade system of the European Union.

Therefore, the Taiwan authorities drum up the European Union incessantly for the negotiation of bilateral investment agreements (BIA) and economic cooperation agreement (ECA), in 2012, the official of economy were sent to Europe as persuaders .On September 29, 2015, Mr. Ma called on personally the EU to start the negotiation on BIA as soon as possible when he was in the video conference with members of the European Parliament.

With its hard work, the economic and trade relations between Taiwan and Europe have made certain progress. The European Parliament passed the "Resolution of relation between the EU and Taiwan on economic and trade " in September 2013, which requested the European Commission begin to negotiate with Taiwan on investment guarantee. That was also the first similar resolution since 1993. The negotiation on investment with Taiwan was mentioned for the first time in the EU's new trade report in 2015.

The two sides also signed two official trade agreements: the "The Security agreement of information exchanges on quality management of original medicine between Taiwan an EU" and cooperation "and" the Exchange notes on trade statistical data between Taiwan and EU. Taiwan has joined finally the European Economic and trade network in 2015, which helps Taiwanese small and medium enterprises to find European trading partners.
In addition, the Ma administration also pays attention to expanding the mechanism of communication and dialogue with the European Union in the field of economic and trade. Besides of the existing annual consultation mechanism, in the promotion, "the European Cooperation Plan in Commerce and Law in Taiwan", which lasts 4 years, started in 2014 with the effect of Ma Administration. It is fully funded by the European Economic and managed by the EETO.

\section{Motivation}

\section{A. Broadening Taiwan's International Space}

At the very beginning of Mr. Ma's Administration in 2008, the Taiwanese Authority pursued a new foreign policy named "modus vivendi", which means "Taiwan and China's mainland stop diplomatic struggle, achieve peaceful coexistence and coprosperity", it abandoned the attempt to establish official diplomatic relations with any other country, and stopped seeking to join international organization as a sovereignty, which replaced by develop substantial relationship in politics and trade relationship in economies. Finally find a new way toward the international community in the way of "dignity", "flexibility" and" pragmatism", and broaden Taiwan's international space without causing a diplomatic dispute.

So, Mr. Ma practiced his idea into his foreign policy, abandoned the attempt to establish official diplomatic relations, but to develop the substantial relationship with the EU members, but deepened all aspects except political relationship, such as trade, Taiwan has signed a number of related trade agreements and memorandums, named "economic diplomacy "with the EU members; and continued to expand dialogue and communication mechanisms with the EU, deepen its ties with the Union in the name of economy and culture; carried out the policy of "visa free", to promote the official visits, strengthen personnel exchanges, and then endowed these economy and cultural relations with obvious political connotation, realize the objective of "expanding the international space" at last.

\section{B. Getting Taiwan's Economy out from Trouble}

Take the year of 2006, which is before the Economic Crisis, as an example, the exportation took up $63.29 \%$ of Taiwanese GDP, this number reached $72.97 \%$ in the year of 2008, and the EU was its forth destination of exportation since 2006, which occupied $11 \%$ of the Export volume, and then the EU is the biggest source of FDI of Taiwan.

To the year of 2009, when the financial crisis overall spread, the drawbacks has been exposed fully, Taiwanese economy has been bloodied, the economic growth rate in 2009 was- $1.81 \%$, the percentage of decline in export is 19.54 , and that of import was 25.91 , the unemployment rate reached 5.85 , the highest record of nearly 30 years, exports accounted for the proportion of GDP to $62.49 \%$. Taiwan's exports to the European Union were equally affected. In 2008, Taiwan's export to the European Union was also influenced and fell by $9.2 \%$, and in 2009 it fell further by $21.8 \%$.

Consequently, to improve the exportation to the EU, It will be necessary to engage with the EU countries on shipping, tax 
issues, and to reduce the cost of Taiwanese investment, increase exports to the EU, that is why the Taiwan authorities try its best to push forward the treaties of BIA and ECA with the EU. In addition, Taiwan is also looking forward to working with the European Union on new energy, communications, construction and other fields, to find new growth points for Taiwan's exports to the EU.

\section{C. "Taiwan-Japan" Relationship was Getting Worse}

"Taiwan-Japan" relationship has been emphasized by the Taiwan authorities, especially in the years when Chen Shuibian, who has Pro-Japanese tendency, in office, it became DPP authorities "key foreign policy", only after Taiwan-US relationship". However, after the Ma Administration came to power, it plunged into the trough because of "nationalization of Diaoyu Islands" and "fishing issues". In particular, Taiwanese representatives in Japan has been recalled during the incident of "nationalization of Diaoyu Islands ", and then, Taiwan and Japan conflicted in the relevant sea areas, which led to the "Taiwan Japan Relations" bottomed out.

Therefore, the Ma Administration promoted the policy toward EU to the second level, and downgrade that of Japan to the third level, which can been seen in the "annual report" of the "Foreign Ministry". Normally, diplomatic policy towards Japan has had a higher level than that of EU for a long time, but this order has been transposed from the beginning of 2009 and the Taiwan-Japan relationship cannot be compared with its relationship with the EU substantially either. Thus, the deterioration of "Taiwan Japan" relationship was an importance external influence factor of Ma's new foreign policy.

\section{CONCLUSION}

With Mr. Ma's work, the Taiwan-EU relationship, which damaged by Chen Shui-bian, has been repaired, and then the both side has signed official agreements much than Mr. Chen's years, and won the "visa free" treatment, but also be included in the trade agreement negotiations. That can be regarded as a great progression, which caused by economic interests and the deterioration of Taiwan Japan relationship.

Fundamentally, Taiwan knew that its "international space" is narrow, and the EU is an important political force international community. Without formal diplomatic relations, Taiwan can maintain the level of communication such only by trade agreements and memoranda, "visa free" and other cultural exchanges, and finally using the existing economic and cultural development and the substantive advantage of "diplomatic relations".

\section{REFERENCES}

[1] Taiwan bureau of foreign trade, MOEA [EB/OL], http://www.trade.gov.tw/App_Ashx/File.ashx?FilePath=../Files/PageFile /c453170a-4127-412e-863b-5dc1c6eee7c8.pd, 2017-2-22.

[2] "The communication between Taiwan and EU"[EB/OL], PChome News, http://news.pchome.com.tw/magazine/print/po/taiwan_panorama/10963/ 142272000019943019001.html,2017-2-23.

[3] EEAS, “EU-Taiwan fact file",2015. 